\title{
Historia de las Tensiones y Posibilidades de la Conservación en Galápagos
}

Nicolás Cuvi ${ }^{1}$

\section{BOOK REVIEW}

Hennessy, Elizabeth. On the Backs of Tortoises. Darwin, the Galapagos, and the Fate of an Evolutionary Eden (New Haven y Londres: Yale University Press, 2019).

En Galápagos, la literatura sobre sistemas socioambientales es menor que la dedicada a su naturaleza biológica. Y en ese campo, son menos aún las perspectivas que, como en el libro de E. Hennessy, combinan la historia ambiental con análisis contemporáneos. Por eso, esta obra se suma a las de investigadores como Ospina (2001) y Grenier (2007), y a otras decenas de documentos clave, producidos durante seis décadas por la Fundación Charles Darwin, el Parque Nacional Galápagos, gobiernos locales y nacionales, e instituciones privadas, nacionales e internacionales, interesadas en el devenir en las islas. 
Muchos de esos estudios se han concentrado en los conflictos entre natura y cultura, ocasionados por cuestiones tan diversas como la colonización, creciente población y turismo, sobrepesca, estudios científicos, entre otros. También han estado enfocados en las intervenciones propuestas, sobre todo desde el conservacionismo, para aliviar esas tensiones. On the Backs of Tortoises es un libro bien recibido en esos debates, pues aporta con análisis singulares, desde aproximaciones teóricas provocadoras y pertinentes, como la agencia de lo nohumano, las relaciones multiespecies o la biopolítica de la conservación.

Es pertinente la metodología, en la que se combinan la observación, entrevistas, participación y revisión de fuentes históricas. Es atrapante el hilo conductor planteado alrededor de las tortugas, centenarios reptiles usados como metáfora desde el título.

El libro tiene 8 capítulos. El primero es una introducción a las islas, las tortugas gigantes y algunos marcos teóricos. A partir de ahí, el recorrido es bastante cronológico, con la virtud de relacionar sucesos del pasado con situaciones contemporáneas. En el capítulo 2, por ejemplo, se narra la cambiante situación de las tortugas, desde ser usadas para preparar sopas, hasta convertirse en atractivos turísticos. En el tercer capítulo se explican varias expediciones científicas, mientras en el cuarto se abordan procesos de colonización. El quinto y sexto capítulos son, en mi visión, los más interesantes y novedosos; ahí se desgrana la construcción de ideas y prácticas de conservación y restauración, mediadas por variopintos personajes e instituciones. En los dos capítulos finales se relacionan esas ideas y prácticas con otras existentes en las islas, no necesariamente simpatizantes de la conservación. Se plantea, de ese modo, la continuidad de los conflictos entre cultura y natura en el archipiélago.

El libro está lleno de detalles sobre asuntos tan variados como los vericuetos sobre la creación de instituciones de conservación desde la década de 1930, o episodios como la extirpación de tortugas, que llevó a algunas especies hasta su extinción. Se da cuenta de la introducción de especies (una historia de larga duración), o de las acciones de los científicos con los animales, desde matarlos para 
museos, hasta estimularlos para que se reproduzcan. Se habla de los ataques de pescadores a tortugas y a la estación. Se retrata a gran cantidad de personajes, sus controversias científicas o políticas, y sus visiones racistas o xenófobas. También se habla del lugar de Galápagos en la geopolítica global. La autora presenta en simetría las voces en conflicto, muchas veces extremas y divergentes, conservacionistas y anticonservacionistas, nacionalistas y globalizadoras, imperialistas y coloniales, desarrollistas y preservacionistas.

La autora es explícita sobre su principal público: muchas de sus motivaciones e inquietudes provienen de diálogos con sus compatriotas "gringos" (así los llama), y la necesidad de debatir discursos como el conservacionismo edénico, antítesis del radical exterminio de la biodiversidad. Alude a algunos protagonistas de esos conservacionismos, en ocasiones retratados como héroes, sin reparos para evidenciar que varias (auto)hagiografías ocultan un pasado imperial, colonialista, racista, lleno de equivocaciones y, en algunos casos, hasta promotor -consciente o inconsciente- de la destrucción de las islas. A diferencia de muchas de esas narrativas, Hennessy no oculta los protagonismos de científicos, políticos, empresarios y pobladores ecuatorianos, sin ser acrítica con ellos. El libro es, de ese modo, un polifónico tejido que da cuenta de diversas formas de vivir, sentir y pensar las islas: fuente de proteína y refugio, laboratorio de la evolución biológica, laboratorio socioambiental, laboratorio de una Utopía social a lo Tomás Moro, espacio de la soberanía nacional y el desarrollo, base militar, Edén que debe ser restaurado, sitio para migrar y huir...

Otra virtud del libro es que alude a algunas pulsiones de vida. Mucha literatura socioambiental sobre las islas, inclusive cosas que yo he escrito, ha sido pesimista. En varios pasajes se desafía las dominantes teleologías de destrucción, y se ilustran posibilidades de arreglos de convivencia con lo no-humano de mayor calidad. Se da cuenta, por lo tanto, de la posibilidad de desafiar la supuesta "maldición de la abundancia" y construir una "biofilia en la abundancia".

Un asunto central son los dilemas de la conservación orientada a la restauración, algo que he discutido con cierto detalle, a propósito de Galápagos, en Cuvi (2016). Se cuestiona la fantasía de lo puro y edénico, y los intereses, contradicciones y biopolítica de ciertos conservacionismos asociados con esas ideas. 
Los discursos y acciones de los biólogos son sujeto de minuciosos escrutinios. Son críticas válidas y valiosas, pero quizás con poca atención a los matices. En Galápagos los conservacionismos extremos han tenido agencia, pero no han sido los únicos que han actuado. La autora misma recuerda que Misael Acosta Solís aludió, hace décadas, a conciliar conservación y producción en el archipiélago, algo que hoy parece normal para la mayoría de conservacionistas. Por momentos, queda la sensación de que el escrutinio es excesivamente duro con el pensamiento conservacionista, y que haría falta reconocer que Galápagos es uno de los pocos lugares del mundo donde la idea de conservación tiene considerable agencia y hasta hegemonía, un poder más allá de lo declarativo. ¿Han sido y son todos los pasos de los biólogos equivocados? ¿Es tan cuestionable una biopolítica que desafía modelos de un mundo homogéneo, planteando perspectivas conservacionistas con distintos grados de radicalidad? Es lógico que exista una moral en el conservacionismo y que tenga biopolítica en su acepción más amplia. En Galápagos, esa singular biopolítica es visible porque ahí es posible. Eso entra en conflicto con visiones comunes al mundo entero, incluidas las de la mayoría de pobladores de las islas, que quieren tener gatos y perros, flores cosmopolitas y plagas. La visión conservacionista entra en conflicto, sin duda, con el economicismo ortodoxo como moral y cosmovisión dominante. En Galápagos la mayoría de gente no es conservacionista, biofílica o biocentrista. En eso es una sociedad similar al resto del mundo. La diferencia es que ese ethos no ha sido, no es, ni, ojalá, será, el más sonoro, por el poder que tiene el conservacionismo de desafiarlo al plantear una moral diferente. Por eso Galápagos es distinto de otros archipiélagos oceánicos como Hawái, Azores o Canarias, donde la conservación es marginal, y donde intensivos procesos de exterminio se han impuesto a lo no-humano.

Esa es, apenas, una de las múltiples tensiones que vuelven al texto atrapante. En las historias se evidencia que, en más de un sentido, las islas son un reflejo del mundo a escala, con la diferencia de que son un verdadero laboratorio de posibilidades para el biocentrismo. Ahí confluyen varios ethos, manifiestos a través de colonos, empresarios, políticos, pescadores, conservacionistas y otros actores, todos en constante pugna por temas que van desde las carreteras, cuotas de pesca o nuevos espacios para urbanizaciones, hasta el deseo de personas por tener gatos que se 
comen los pinzones, pero que al mismo tiempo reclaman participar en los réditos del turismo que llega a las islas para conocer a los pinzones. El libro es punzante, porque revela esas y otras paradojas de las relaciones entre sociedad y naturaleza que, al menos en las islas, parecen mantenerse sin solución de continuidad.

\section{REFERENCIAS}

Cuvi, Nicolás. "Ética ambiental, conservacionismo y evolución." En Evolucionismo en América y Europa. Antropología, biología, política y educación, editado por Nicolás Cuvi, Elisa Sevilla, Rosaura Ruiz y Miguel Angel Puig-Samper, 393-410 (Madrid y Quito: Doce Calles, FLACSO Ecuador, UNAM y PUCE. 2016).

Grenier, Christophe. Conservación contra natura. Las islas Galápagos (Quito: Instituto Francés de Estudios Andinos, Embajada de Francia en el Ecuador, Institut de Recherche Pour le Devélopment, Universidad Andina Simón Bolívar y Abya-Yala, 2007).

Ospina, Pablo. Migraciones, actores e identidades en Galápagos (Buenos Aires: CLACSO, 2001). 